\title{
Physicochemical Characteristics of Soil from Selected Solid Waste Dump Sites in Port Harcourt, Rivers State, Nigeria
}

\author{
*11OBIANEFO, FU; ${ }^{1}$ AGBAGWA, IO; ${ }^{1}$ TANEE, F.B.G \\ ${ }^{I}$ Department of Plant Science and Biotechnology University of Port Harcourt, Rivers State, Nigeria \\ flobianrich@gmail.com
}

\begin{abstract}
This study examined the nutrient status and textural characteristics of soil from solid waste dumpsites in the city of Port Harcourt. The study was carried out in five solid waste dump sites alongside their respective controls located at Iwofe, Eliozu, Choba, Rumuokwuta and Ozuoba within the city of Port Harcourt for two seasons (wet and dry). A systematic sampling technique was employed for field sampling. Soil sample was collected with soil auger and analysis was done using standard methods. Results showed mean $\mathrm{pH}$ value $(4.86 \pm 0.18-7.66 \pm 0.44)$ and; cation exchange capacity $(2.2 \pm 0.3-18.11 \pm 0.8 \mathrm{meq} / 100 \mathrm{~g})$. The mean electrical conductivity indicated higher conductivity in the control sites $(125 \pm 5.5-492 \pm 16 \mu \mathrm{s} / \mathrm{cm})$ than the dump sites $(32.06 \pm 2.5-299.5 \pm 1.5 \mu \mathrm{s} / \mathrm{cm})$. There was high nutrient concentrations in the dump site soils of total nitrogen $(0.04 \pm 0.01-0.62 \pm 0.13 \%)$; phosphorus $(0.041 \pm 0.01-$ $4.07 \pm 0.02 \mathrm{mg} / \mathrm{kg})$; potassium $(9.19 \pm 2.5-326 \pm 51.91 \mathrm{mg} / \mathrm{kg})$ than the controls. On the contrary, there was no significant difference between the soil particle size distribution of the dump site soil and their respective controls. The soil particle size distribution indicated an average of $83 \%$ sand, $11 \%$ clay and $5 \%$ silt, while the soil texture was loamy sandy for all the dump sites except the dump site located at Iwofe. Therefore, solid dumps alter the soil nutrient contents with no significant change in the textural nature of soil. (C) JASEM

https://dx.doi.org/10.4314/jasem.v21i6.27
\end{abstract}

Key words: Solid wastes, Soil, Particle size, Nitrogen, Nutrient, Dump sites

Systematic depletion of public health and general living conditions of a given populace is largely traceable to the adaptation of man to his less than wholesome environment. Man, as an active member of his ecosystem, defined by where he lives, sources of his food, including water and even the air he breathes, is constantly exposed to the hazards of wrong applications, utilization and consumption patterns.

In the past waste disposal was not taken too seriously in the developing countries, but in recent years with increase awareness of the environmental hazard caused by wastes, much concern has been directed to its management (Igwe et al., 2002). The increase in population coupled with rural-urban drift has increased the quantity of wastes generated in the urban areas and the developing countries are faced with not only the challenge of collecting the wastes but how and where to dispose of it without causing further environmental hazard (Ogunleka, 2009; Oguche, 2013).

Port Harcourt, one of the major cities in Nigeria is host to oil companies, industries, health centers, institutions and markets and is faced with rapid deterioration of the environmental condition due to the conventional system of collection and disposing of solid wastes. Wastes found in the dump sites come from municipal, domestic and industrial sources and may contain heavy metals (Babatunde et al., 2014).
The management of these wastes generated in the city (urban areas) has become a serious problem because; little efforts have been made in order to improve on the wastes collection and disposal facilities. This is not without their consequence such as deteriorating soil quality (Obute et al. 2010; Ideriah et al. 2010).

This study is carried out to determine the nutrient status and particle size distribution of soil samples from solid waste dump sites.

\section{MATERIALS AND METHODS}

Study Area: In this study, five solid waste dump sites located in Port Harcourt of the Niger Delta area of Nigeria were selected. The dumpsites selected were located at Iwofe $\left(04^{0} 54^{\prime} 16.4^{\prime \prime} \mathrm{N}, 006^{0} 55^{\prime} 8.6^{\prime \prime} \mathrm{E}\right)$, Eliozu $\left(04^{0} 53^{\prime} 07.4^{\prime \prime} \mathrm{N}, 007^{0} 00^{\prime} 50.1^{\prime \prime} \mathrm{E}\right)$, Choba $\left(04^{0} 5334.1^{\prime \prime} \mathrm{N}\right.$, $\left.006^{0} 54^{\prime} 48.7^{\prime \prime} \mathrm{E}\right), \quad$ Rumuokwuta $\left(04^{0} 50^{\prime} 43.70^{\prime \prime} \mathrm{N}\right.$, $\left.006^{0} 58^{\prime} 55.6^{\prime \prime} \mathrm{E}\right)$ and Ozuoba $\left(04^{0} 5203.2^{\prime \prime} \mathrm{N}\right.$, $\left.006^{0} 57^{1} 37.2^{\prime \prime} \mathrm{E}\right)$. A control was selected for each dumpsite. The control was located at a distance of 200 meters from the dumpsite. The names of the locations of the dump sites were adopted to represent the different dump sites.

Sample Collection: Sampling was done at wet and dry seasons beginning from September 2015 to December 2016 covering two wet and two dry seasons. The systematic sampling technique was used for sampling. A transect line was laid across a mapped out area of $20 \mathrm{~m}$ by $20 \mathrm{~m}$ and a quadrant of 
$1 \mathrm{~m}$ by $1 \mathrm{~m}(1 \mathrm{~m} \times 1 \mathrm{~m})$ was placed on the first marked point on the line. Sampling was done at $5 \mathrm{~m}$ interval all the way down the line given a total of four sample plots at each dump site. Soil samples were collected at $0-15 \mathrm{~cm}$ with a soil auger for physicochemical analysis.

Determination of Physicochemical characteristics of Soil: The soil texture and nutrient status were determined using standard method as outlined in the International Institute of Tropical Agriculture (IITA) 'Selected Materials for Soil and Plant Analysis (1991). The $\mathrm{pH}$ of the soil sample was determined using $\mathrm{pH}$ meter model HANNA HI8314. The electrical conductivity was determined using the conductivity meter model HANNA HI 98303. The soil texture was determined using the hydrometric method. Total nitrogen in soil was done using the Macro-kjeldahl digestion method (Black, 1965).The Bray no.1method was used to determine the phosphate in the soil.The ammonium acetate method was used to determine the cation exchange capacity and the available potassium in soil.

Data Analysis: The Data collected were statistically analyzed using descriptive statistics (mean, and standard error) and two - way ANOVA.

\section{RESULTS AND DISCUSSION}

The characteristics of soil may vary and its physical, chemical and biological properties may be influenced by the activities of the environment. Hence these properties determined the capability of the soil to promote plant growth.

In this study it was observed that the $\mathrm{pH}$ of the soil ranged between moderately acidic $4.8 \pm 0.18$ and slightly above neutral $7.66 \pm 0.44$ (Figure1). The higher $\mathrm{pH}$ level in the dump sites than their controls has been reported to be as a result of liming materials and also the activities of some microorganism on the solid wastes (Ayade, 2003, Ideriah et al., 2006). Furthermore, $\mathrm{pH}$ has been reported as a simple and direct measure of the overall chemical condition of the soil and at $\mathrm{pH} 6.5$, nutrients availability to plants from the soil is at its highest (Praveena and Rao, 2016). The solubility of nutrients in the soil has been reported to be correlated to $\mathrm{pH}$.

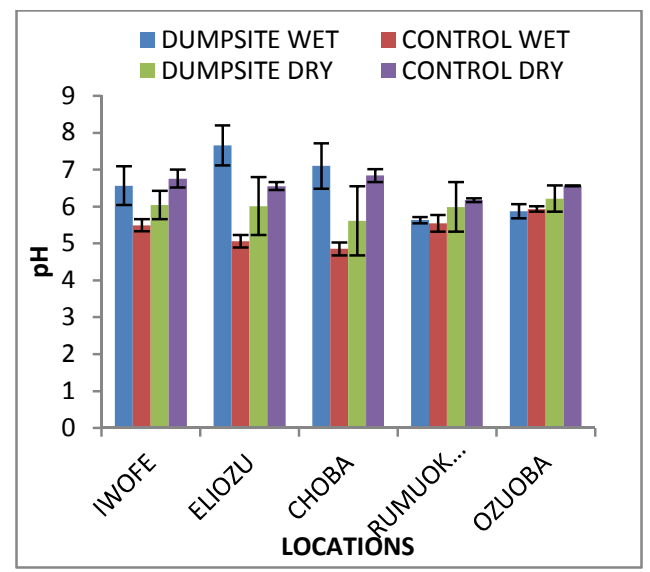

Fig 1: The mean $\mathrm{pH}$ in the study location for wet and dry season.

In all the dumpsites studied the soil cation exchange capacity was lower than the control (Figure2). This suggests that the solid waste might have distorted the soil natural ability to retain nutrients.

The relatively high level of electrical conductivity in the dry season (Figure 3) indicates the role of season in the soil as flood water from the wet season helps to dilute the solutes and mineral components of the wastes which may have accounted for the low conductivity in the wet season (Obianefo et al., 2016).

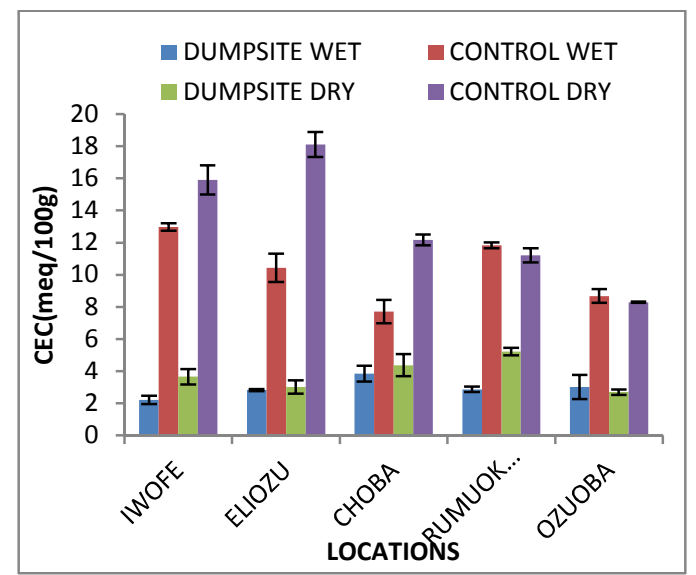

Fig 2: The mean concentration of the cation exchange capacity in the study locations for dry and wet season. 


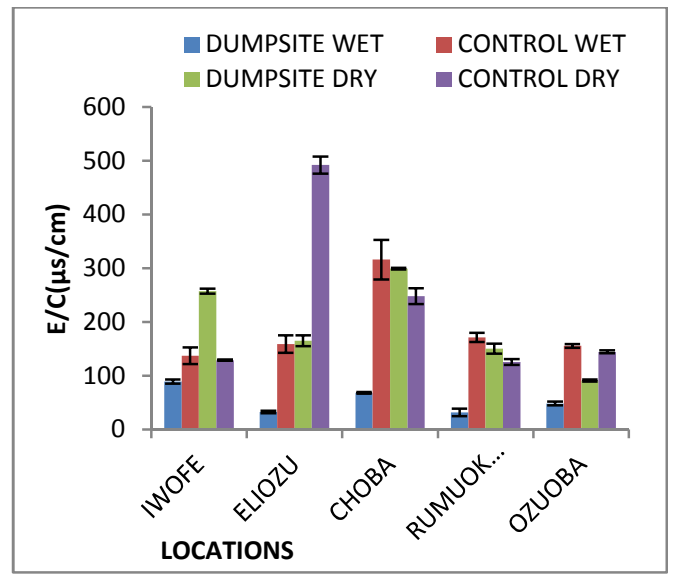

Fig 3: The mean concentration of the Electrical Conductivity in the study locations for dry and wet season.

Solid waste dumpsites have been reported to be rich in organic matter which is the source of most of the nitrogen and phosphorus which enhances soil fertility and promote plant growth (Ideriah et al., 2010). The total nitrogen in the dump site soils was higher as compare to the control locations (Figure 4). This might have been due to the composition of the wastes which were mainly from agricultural and farmyard sources. Also the activities of soil organisms in the decomposition of these wastes may have accounted for the rich nutrient contents of the soil (Obute et al., 2010; Amos-Tautua et al., 2014).

Results showed high level of phosphorus and potassium (Figures 5 and 6) in the dump sites especially in the wet season as compare to the control sites. The high level of these nutrients can be attributed to the composition of the wastes since majority of the wastes come from household with high organic matter content. It has also been reported that high phosphate reduces the availability of cation metals to plant (Brady and Weil, 1999).

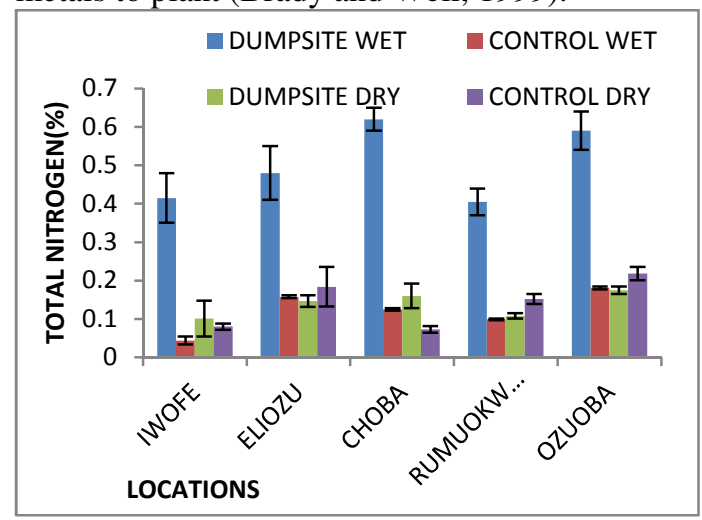

Fig 4: The mean concentration of total nitrogen in the study locations for dry and wet season.

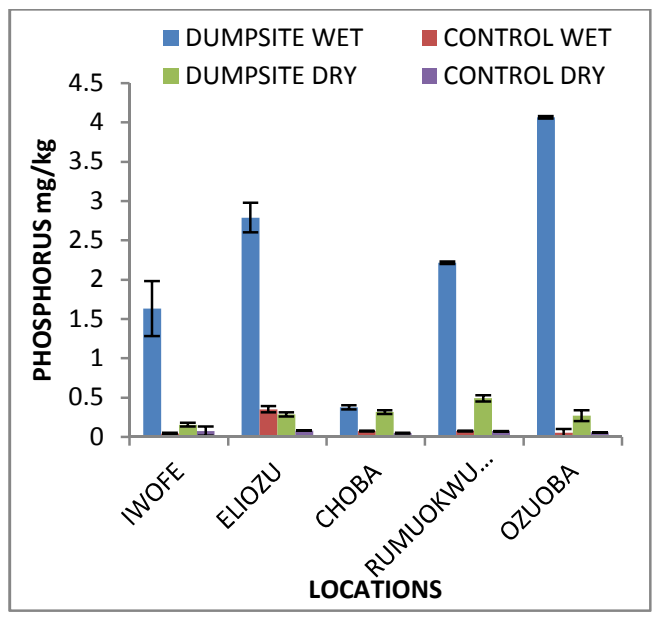

Fig 5: The mean concentration of phosphorus in the study locations for dry and wet season.

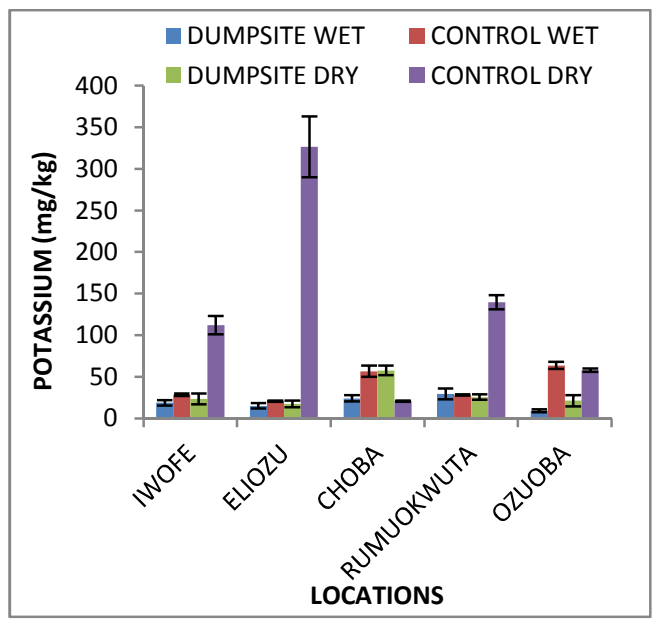

Fig 6: The mean concentration of potassium in the study locations for dry and wet season.

The soil particle size distribution was between $76 \%$ $86 \%$ sand $8 \%-17 \%$ clay and $2 \%-8 \%$ silt for the dumpsites and the control $76 \%-85 \%$ sand, $8 \%$ $18 \%$ clay and $5 \%-9 \%$ silt (Figures 7-9) which has been reported in the soil found in the Niger Delta area (Ayade, 2003). The low clay percentage can be suggested for the low cation exchange capacity since clay in the soil determines its water retention capacity and also the volume of water is directly related to the pore spaces in any given soil. It was observed that the soil textural class of the dump sites studied was mostly loamy sandy except for the Iwofe dump site which was sandy soil. This has also been reported in similar study that decomposition of agricultural wastes influence the texture of the soil (Ideriah et al., 2006). 


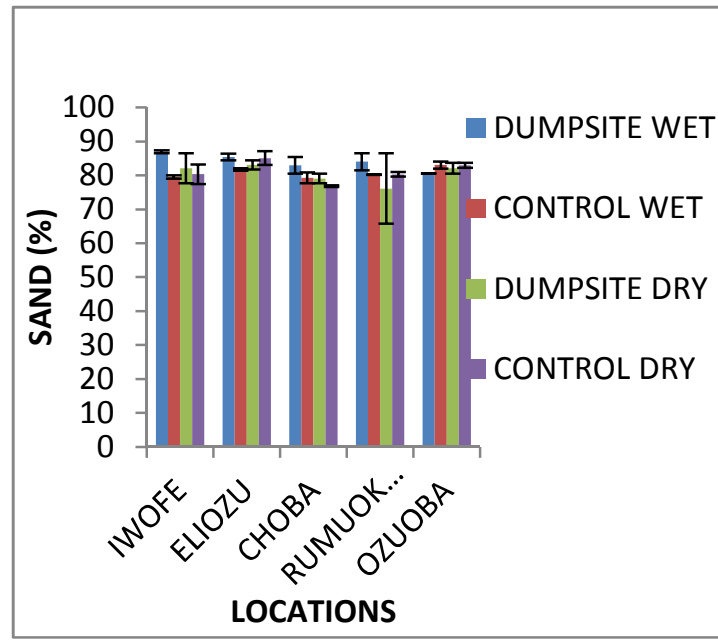

Fig 7: The mean sand percentage in the study locations for wet and dry seasons.

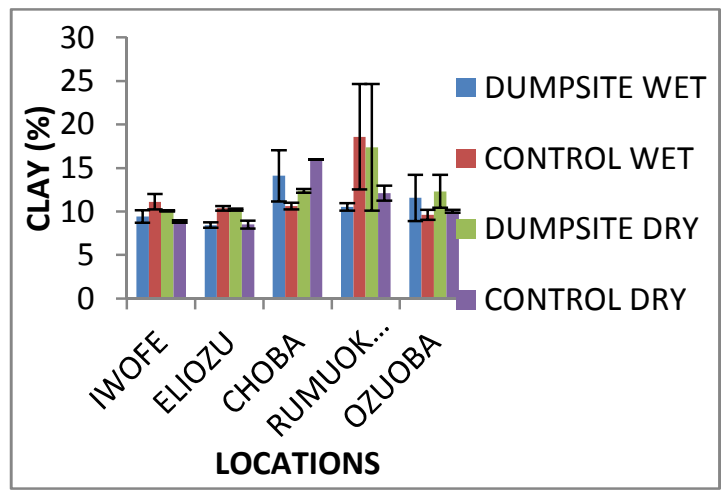

Fig 8: The mean clay percentage in the study location for the wet and dry seasons.

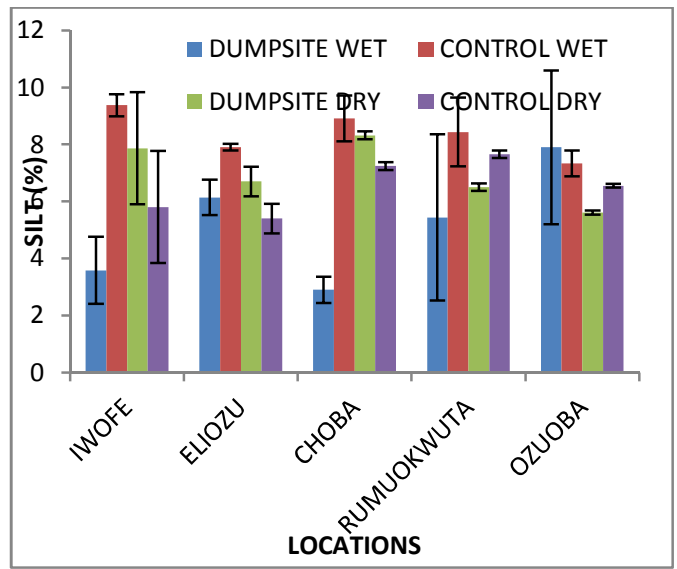

Fig 9: The mean silt percentage in the study location for wet and dry seasons.

Conclusion: From this study, the soil in solid waste dump sites has been observed to be rich in soil nutrients. Also this study has shown that the soil particle size distribution has not been remarkably altered by the effect of solid wastes. However, there is a need for continuous monitoring and evaluation of these dumpsites for possible metal contamination and toxicity.

\section{REFERENCES}

Amos-Tautua, BMW; Onigbinde AO; Ere, D (2014). Assessment of some heavy metals and physiochemical properties in surface soils of municipal open waste dumpsite in Yenagoa, Nigeria. Africa Journal of Environmental Science and Technology, 8(1):41-47.

Ayade, BB (2003). Indigenous biological treatment of hydrocarbon contaminated soil in the tropics. Journal of Nigerian Environmental Society, 1(1):87-94.

Babatunde, BB; Vincent-Akpu, IF; Woke, GN; Atarhinyo, E; Aharanwa, UC; Green, AF;Isaa-Joe, O (2013). Comparative analysis of municipal solid waste composition in three Local Government Area in Rivers State Nigeria African Journal of Environmental Science and Technology, 7(9):874-881.

Black, CA (1965). Methods of Soil Analysis Agronomy No.9 Part 2 Amer. Soc. Agronomy, Madison. Wisconsin.

Brady, NC; Weil, RR. (1999). The Nature and Property of Soil. $12^{\text {th }}$ ed. Prentice hall. Upper Saddle River,NJ.

Ideriah, TJK; Omuaru, VOT; Adiukwu, PU (2006). Soil quality around asolid waste dumpsite in Port Harcourt. African Journal of Ecology, 44(3):388-394.

Ideriah, TJK; Harry, FO; Stanley, HO; Igbara, JK (2010). Heavy metal contamination of soils and vegetation around solid waste dumps in Port Harcourt, Nigeria. Journal of Applied science Envrionmental Mangement, 14(1):101-109.

Igwe, C; Isirimah, NO; Teme, SC (2002). Distribution and characteristics of solid wastes and waste disposal sites in port Harcourt municipality, Rivers State, Nigeria. African Journal of Environmental Pollution and Health, 1(2):51-60.

Obianefo, FU; Chindah, AC; Ochekwu, EB (2016). Water quality and Phytoplankton distribution Nta-wogba stream receiving municipal discharges in Port Harcourt, Rivers State Nigeria. Research Journal of Environmental Toxicology, 10:135-143.

Obute, CC; Ndukwu, BC; Eze, E (2010). Changes in species diversity and physic-chemical properties of plants in abandoned dumpsites in parts of Port Harcourt, Nigeria. Scientia Africana, 9(1): 181-193.

Oguche, JA (2013). Spatial location of solid waste dumpsites and collection scheduling using the geographic information systems in Bauchi Metropolis Nigeria. European scientific Journal, 9(11):374-382

Oguneleka, TCH (2009). Municipal solid waste characteristics and management in Nigeria, IranianJournal of Environmental Health Science and Engineering, 6(3): 173-180.

Praveena, SG; Rao, PV (2016). Impact of leachate on soil properties in the dumpsite. International Journal of Engineering Research and General Science, 1:235. 